\title{
3D numerical simulation of clastic reservoir with bottom water drive using various ior techniques for maximizing recovery
}

\author{
Pushpa Sharma $^{1} \cdot$ Manish Kumar $^{2}$ (D) D. K. Gupta ${ }^{1}$
}

Received: 9 March 2018 / Accepted: 21 July 2018 / Published online: 30 July 2018

(c) The Author(s) 2018

\begin{abstract}
In most reservoirs with oil rims, as the production begins, the gas-oil and oil-water fluid interfaces start deforming because of the imbalance between viscous and gravitational forces, leading to coning or cusping. This can be overcome using proper withdrawal rate, offset from water-oil contact and horizontal length. Further smart horizontal wells require optimization of nozzle size and compartment length also. To see the effect of these parameters on recovery, a three-dimensional geological model of a clastic reservoir from Upper Assam Basin has been used. This model was history matched for a period of 16 years on 46 wells. After successful validation of model on field scale and well level, performance prediction was carried out to see the effect of withdrawal rate, offset from water-oil contact, horizontal length, compartment length and nozzle size using vertical/horizontal and ICD completion. From the analysis, it is evident that application of advanced well completion, ICD, is suitable for such reservoir. Depending on the scenario, maximum cumulative oil production was obtained from ICD wells with $1.08 \mathrm{MMm}^{3}$ compared to vertical well with cum oil production of $0.63 \mathrm{MMm}^{3}$. Economic analysis has been carried out for the examined scenarios.
\end{abstract}

Keywords Field development $\cdot$ ICD $\cdot$ Undrained oil $\cdot$ Water injection $\cdot$ Recovery

\section{List of symbols}

ICD Inflow control device

EOS Equation of state

FDP Field development plan

FWL Free water level

GOR Gas-oil ratio

HCPV Hydrocarbon pore volume

SCAL Special core analysis

THP Tubing head pressure

TVDSS True vertical depth below sea level

K Permeability (mD)

$\mathrm{Kh} \quad$ Horizontal permeability $(\mathrm{mD})$

ko Oil permeability $(\mathrm{mD})$

$\mathrm{Kv} \quad$ Vertical permeability $(\mathrm{mD})$

lab Laboratory

MM Million metric

NPV Net present value

Manish Kumar

manish@oilindia.in

1 University of Petroleum and Energy Studies, Dehra Dun, India

2 CoEES, Oil India Ltd., Guwahati, India

$\begin{array}{ll}\text { WOC } & \text { Water-oil contact } \\ \text { Pc } & \text { Capillary pressure } \\ \text { Greek symbols } \\ \varrho_{\mathrm{w}} & \text { Water density }\left(\mathrm{lbm} / \mathrm{ft}^{3}\right) \\ \varrho_{\mathrm{o}} & \text { Oil density }\left(\mathrm{lbm} / \mathrm{ft}^{3}\right) \\ \phi & \text { Porosity (fraction) } \\ \sigma & \text { Surface tension } \\ \mu_{\mathrm{o}} & \text { Oil viscosity } \\ \theta & \text { Contact angle (degrees) }\end{array}$

\section{Introduction}

The study on remaining oil in high water cut oilfield is a fundamental for oilfield development and enhanced oil recovery, which is a worldwide highly comprehensive research problem and hot issue. Today, advanced technologies of horizontal drilling and application of advanced well completion such as ICD turn the development of unswept oil into a reality.

Extreme water production is one of the main reasons which contribute in decrease of productivity of wells. Rising water cut influences inflow performance and tubing performance curve negatively. Excessive water production 
enhances the expenditure of lifting of fluids to surface, treatment of water, and disposal. Production of water is also related to scale formation at different production system components (Al Hasani et al. 2008).

Determining good well locations and completions of production and injection wells are important to optimally develop and produce a reservoir (Forouzanfar and Reynolds 2013). Dosunmu and Osisanya (2015) show that horizontal well productivity is significantly affected by oil viscosity, horizontal permeability, and well diameter. Al Qahtani et al. (2015) showed a noble idea of taking full advantage of long horizontal well if it is produced from both ends, i.e. from heel and toe.

Oil recovery is increased by appropriate selection of ICD, which also stops flow of unwanted production of water and gas. Results obtained from fields and simulation studies show that production of oil, gas, and water is very much dependent on the type of ICD and number of ICD used (Mojaddam Zadeh et al. 2012).

Well placement in a bottom water drive reservoir poses several challenges. The real oil fields are complex environments due to heterogeneities, presence of geologic discontinuities (e.g., faults, fractures, and very high and low permeability zones), and geologic uncertainties. Moreover, coning tendency in vertical well leads to early water breakthrough, which can be avoided using horizontal well placement techniques with optimized length, rate and offset. Further smart horizontal wells are also being used extensively for maximizing recovery. A proper methodology needs to be developed for avoiding early water breakthrough and increase water-free production.

Objective of the study is to carry out sensitivity study on offset, withdrawal rate, horizontal length, compartment length and nozzle sizes in three-dimensional numerical simulation model.

\section{Methodology}

In this work, methodology adopted for determination of optimum variants for vertical well, horizontal well and smart horizontal well is given below.

- Static modeling.

- History matching.

- Sensitivity analysis.

- Vertical well (offset from woc, withdrawal rate).

- Horizontal well (offset from woc, withdrawal rate, horizontal length).

- Smart horizontal well (compartment length, nozzle size).

- Economics and recovery factor.
Fig. 1 Fault pattern of the reservoir

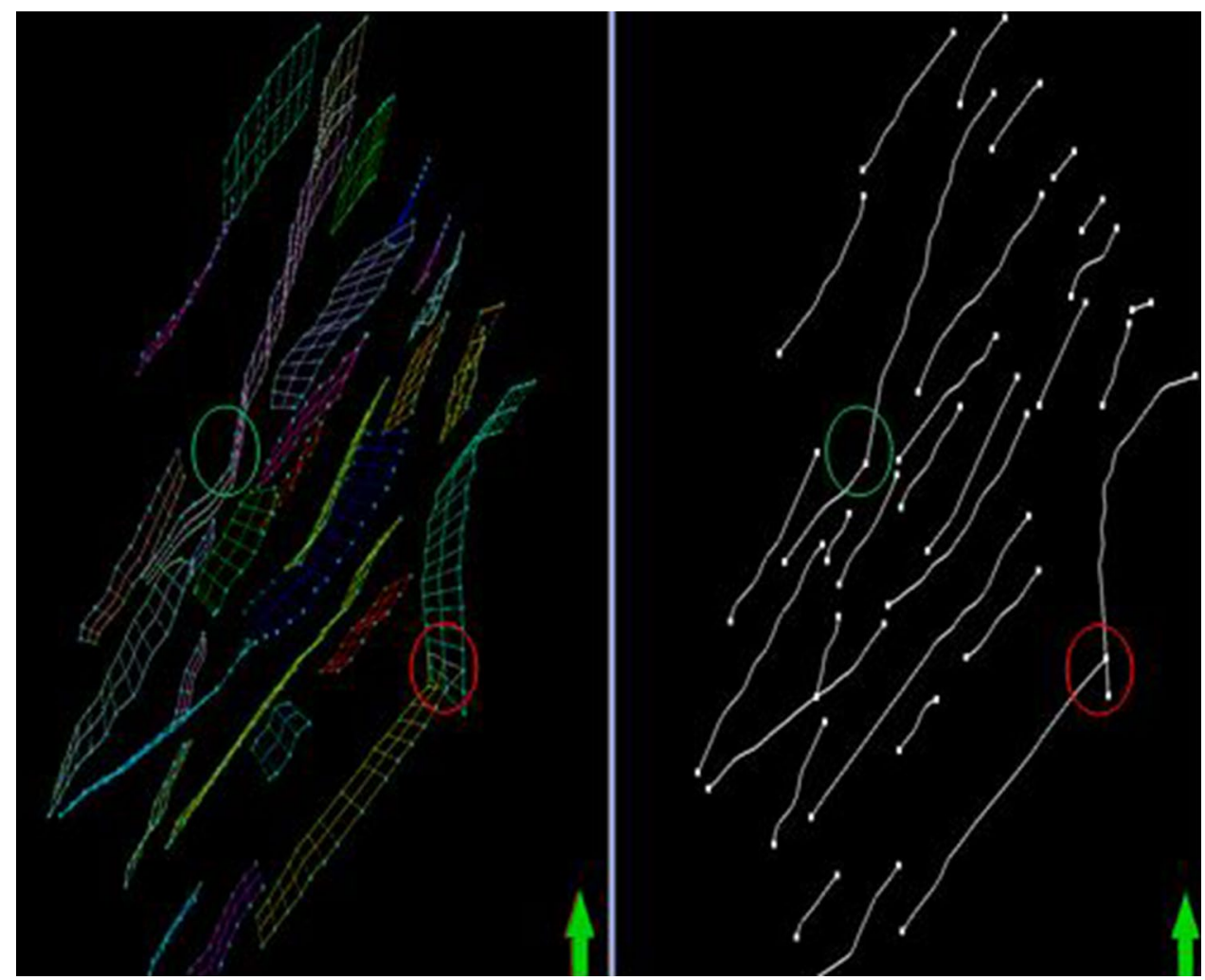




\section{Static modeling}

Pillar gridding process in petrel is used to make the static model. The original model was kept intact with minor modifications. A number of NE-SW trending normal faults of limited lateral continuity intersects the structure at the Barail Arenaceous level. Figure 1 shows the fault pattern of the reservoir.

Geological grid was made with cell size $75 \mathrm{~m} \times 75 \mathrm{~m}$ using grid rotation of $40^{\circ}$. Once the grid was made, structure and properties were upscaled and the total number of cells in the model is now 1,035,960. The total number of

Table 1 Statistics for different rock type

\begin{tabular}{lcrcc}
\hline Rock type & \% fraction & So $\%$ & $\langle\mathrm{~K}(\mathrm{md})\rangle$ & $\langle$ Phi \% $\rangle$ \\
\hline 1 & 14.5 & 60.44 & 1157 & 22.25 \\
2 & 28.5 & 51.64 & 502 & 20.73 \\
3 & 33.1 & 37.66 & 220 & 18.29 \\
4 & 8.1 & 7.11 & 180 & 15.44 \\
5 & 15.8 & 1.35 & 157 & 10.96 \\
\hline
\end{tabular}

cells present in the geomodel prior to upscaling is $8,171,520$ which were further upscaled to $100 \times 100$.

Five different rock types (RT) have been kept in the model (RT 1-5). RT 1 is the best rock type where as RT 5 is bad rock type in the study. Rock-type statistics expressed in terms of porosity, permeability and oil saturation is presented in Table 1. Porosity, permeability and reservoir thickness distribution of the geocellular model (GCM) have been shown in Figs. 2, 3 and 4, respectively.

\section{History match}

Observed data (oil, gas, water rates and pressure data) for 46 wells for duration of 16 years was computer generated with an industry standard simulator. Outcome of the history match on reservoir level is illustrated in Fig. 5. Wellwise flowing/static pressure data, gas-oil ratio and water cut were used as parameters for history matching. From Fig. 5, it is evident that GOR, pressure, water rate, oil rate have been matched reasonably well with the observed data by the industry standard simulator at field scale.

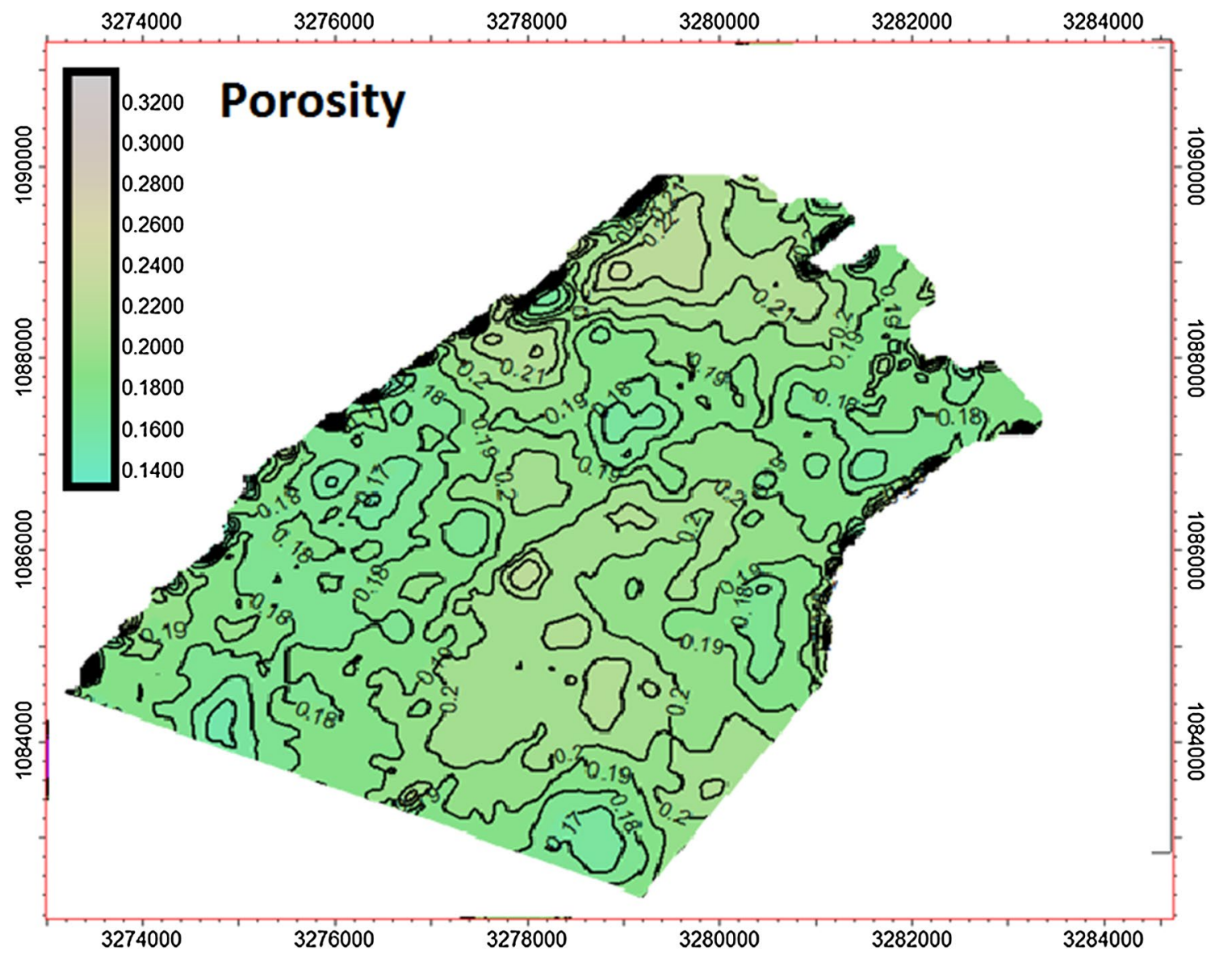

Fig. 2 Porosity distribution 


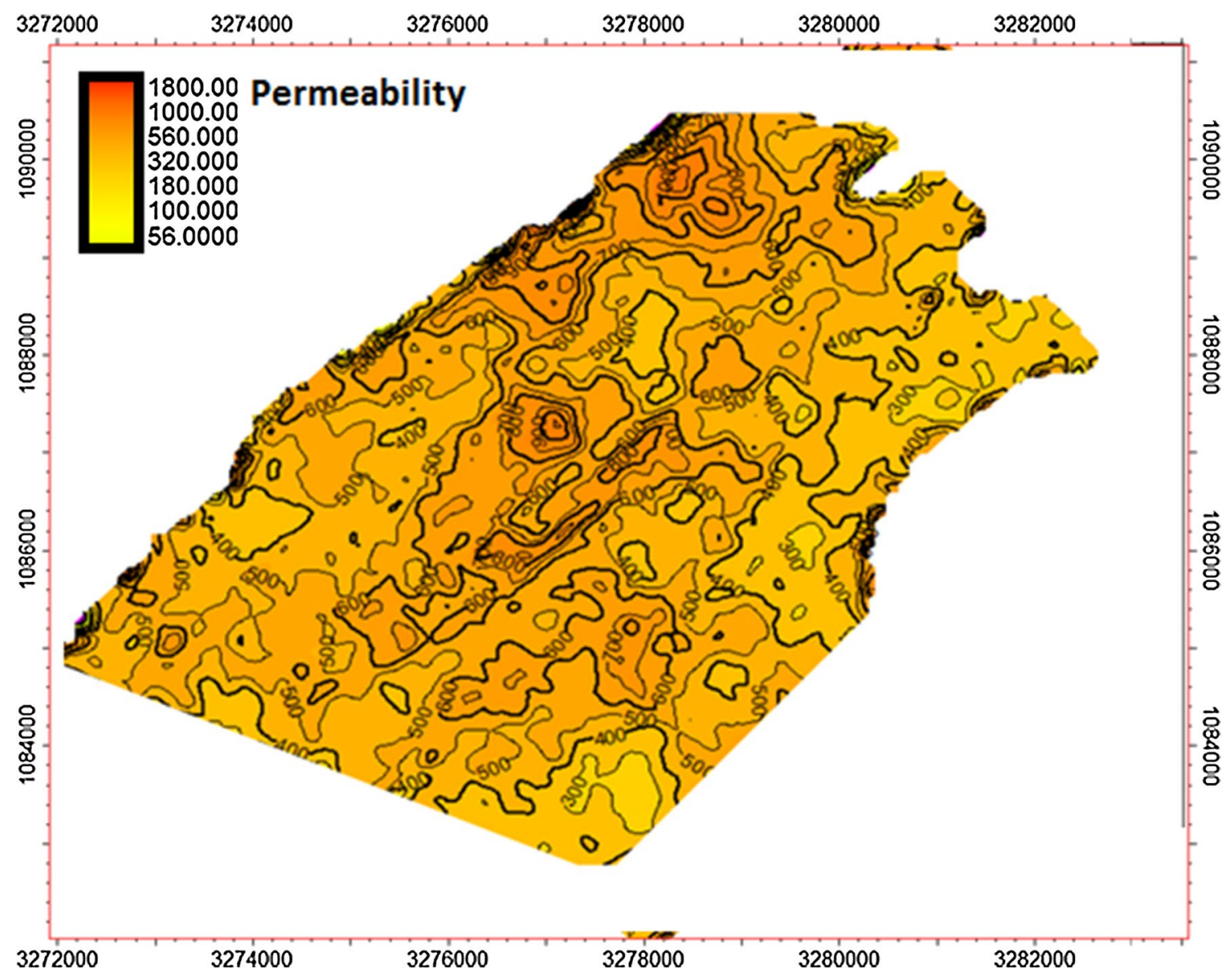

Fig. 3 Permeability distribution

\section{Performance prediction}

The oil flow rate, vertical and horizontal permeability, oil viscosity, oil formation volume factor, oil-water mobility ratio and the perforation interval length are the major factors which affect the breakthrough time of water and gas (Wagenhofer and Hatzignatiou 1996). Evaluation of some of these parameters has been carried out to see their effect on production behavior. Performance prediction of the simulation case has been carried out in three parts, which is listed below:

vertical well (offset from WOC, withdrawal rate).

Horizontal well (offset from WOC, withdrawal rate and horizontal well length).

Smart horizontal well (compartment length, nozzle sizes).

\section{Sensitivity study of vertical well—offset and withdrawal rate}

The history-matched model was used to perform sensitivity studies on offset from WOC and withdrawal rate. All variants are been mentioned in Table 2. From all combinations mentioned in Table 2, 15 cases were constructed, details of which is mentioned in Table 3.

All sensitivity studies in prediction mode were simulated using production rate control mode. Constraint on production at well scale was specified as per the capacity of surface handling equipments. Apart from above constraints, wells were subjected to some additional constraints which is shown in Table 4.

\section{Sensitivity study of horizontal well-offset, withdrawal rate and horizontal length}

The history-matched model was used to perform sensitivity studies on offset from WOC, horizontal well length and withdrawal rate. All variants are mentioned in Table 5. From these grouping 48 cases were prepared, details of which is given in Table 6.

All sensitivity studies in prediction mode were simulated using production rate control mode. Constraint on production at well scale was specified as per the capacity of surface handling equipments. Apart from above constraints 


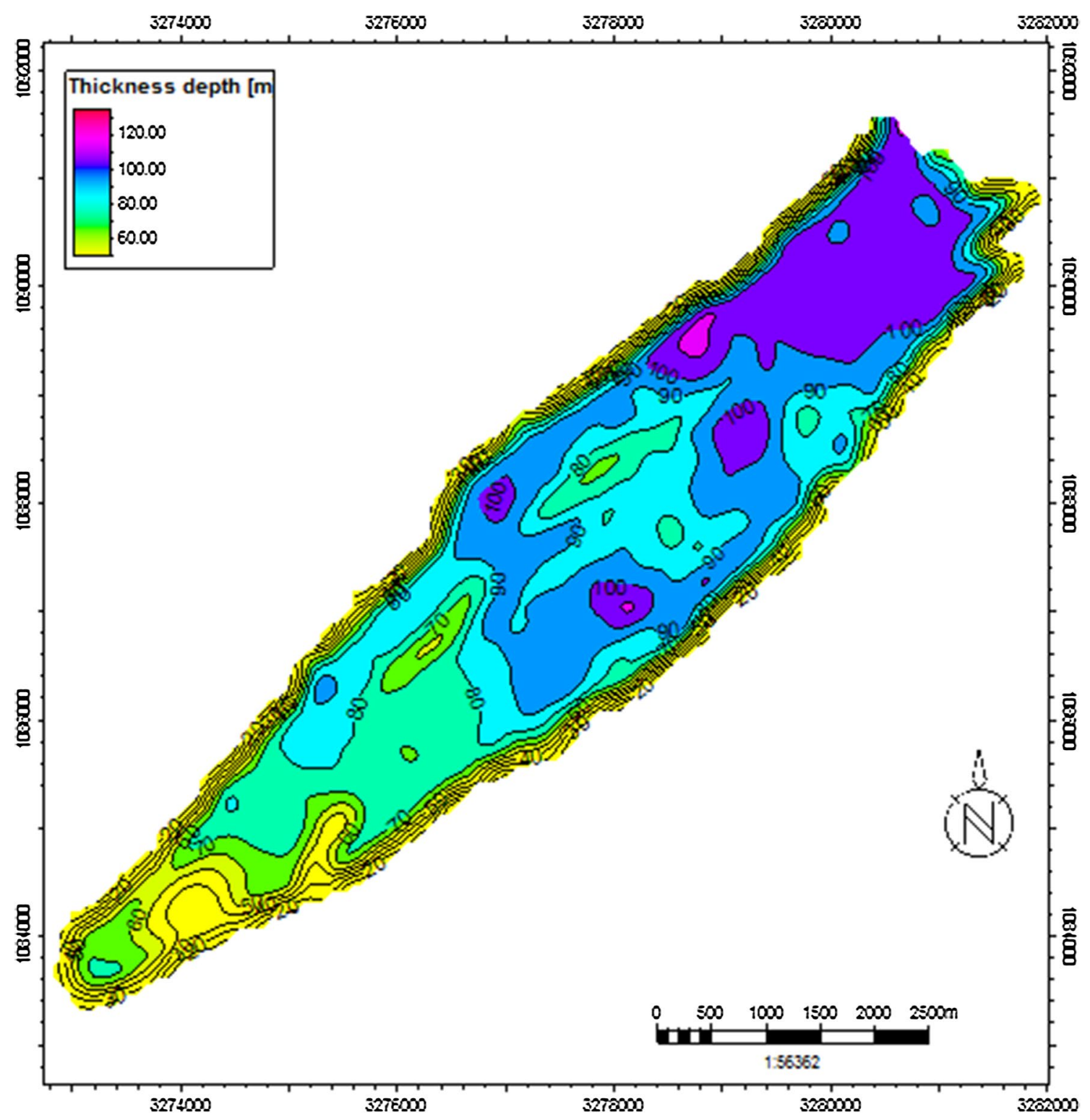

Fig. 4 Reservoir thickness distribution

wells were subjected to some additional constraints which is shown in Table 4.

\section{Sensitivity study of inflow control device- compartment length and nozzle sizes}

A horizontal well does not contribute equally throughout its length. Heel contribution of production is more than from toe because of frictional pressure drop along wellbore length, which leads to non-uniform influx throughout the wellbore length. This effect also known as heel-toe effect which leads to reduced recovery of oil because of early water/gas breakthrough and uneven area swept area near producing well. To resolve this issue, inflow control device (ICD) has been widely used in producing wells for controlling and optimizing individual well or overall reservoir performance. The sole purpose of ICDs is to make equal inflow along the entire wellbore length despite location and permeability variation. Application of ICDs allows the entire horizontal length of the wellbore to add 

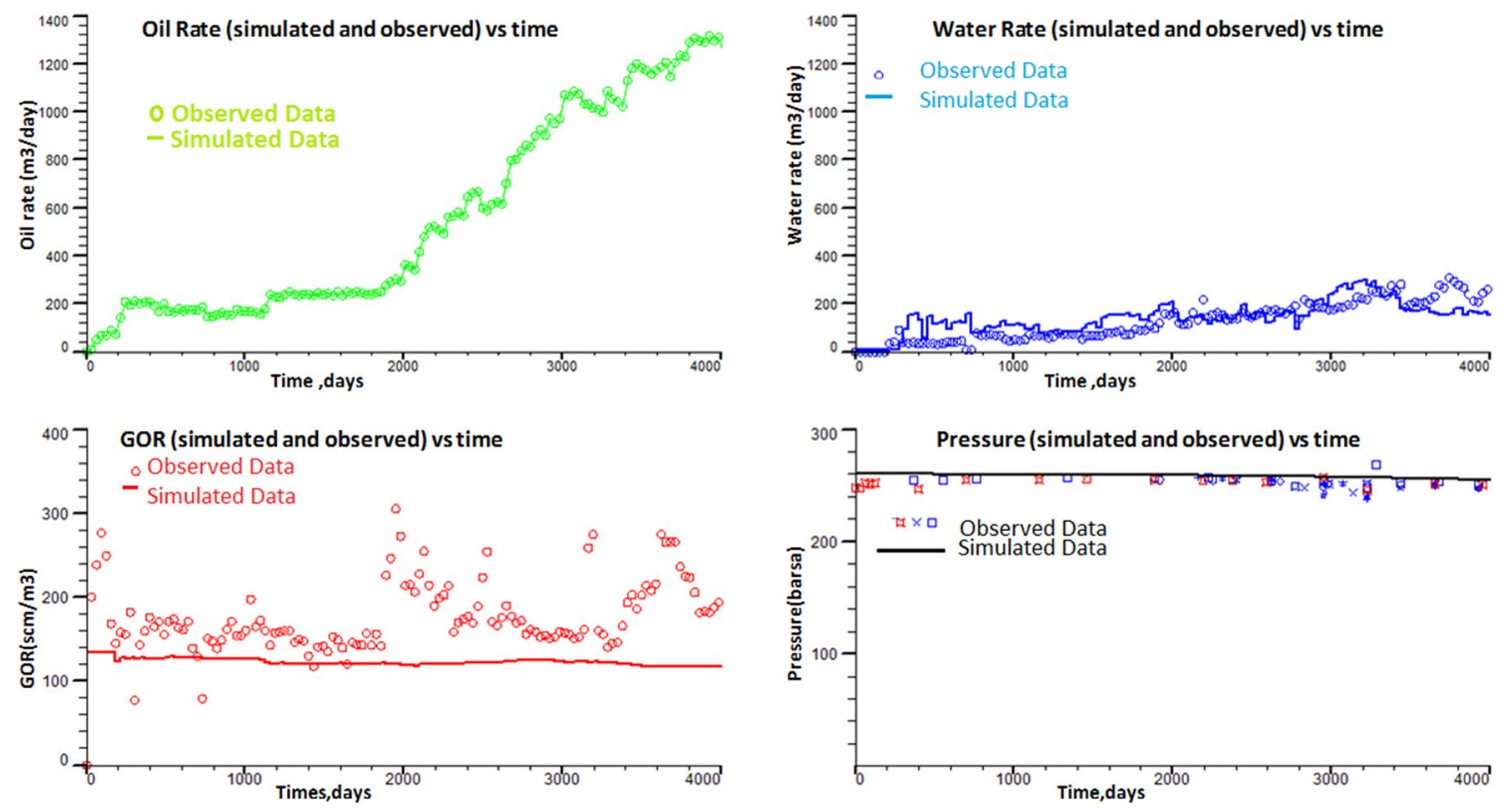

Fig. 5 History match results

Table 2 Sensitivity parameters for vertical well

\begin{tabular}{lllllll}
\hline Rate (m ${ }^{3} /$ day) & 50 & 100 & 150 & & \\
Offset (perforation bottom) from WOC (m) & 0 & 5 & 10 & 15 & 20
\end{tabular}

to the total production and thereby optimize hydrocarbon recovery.

Careful choice of ICD increases the oil recovery and constrains unwanted production of water and gas. IT has been observed from actual field experience and outcome from the extensive simulation studies that the oil, water and gas production are extremely reliant on the type and arrangement of ICD (Mojaddam et al. 2012). A suite of optimized ICD modeling workflows and evaluation tools were developed to address these issues using a plug-in architecture in an industry-leading exploration and production platform (Schlumberger PETREL 2015) and reservoir simulator (Schlumberger 2015) Historically, the most common method for designing ICD completions has been to use steady-state or pseudo steady-state (i.e. static) analytical modeling using data at one or more points in time (Ellis et al. 2009).

ICD design has been done using equal length compartment and variable nozzle sizes in each ICD.

\section{Equal length compartments with uniform nozzle sizes- sensitivity on packer length}

A design with equally spaced compartments and uniform nozzles sizes is preferred if there is significant uncertainty in the reservoir characterization or risk in getting the 
Table 4 Well level constraints for prediction runs

\begin{tabular}{lc}
\hline Constraints & Value \\
\hline Maximum individual well production rate & $\begin{array}{r}\text { Decided based on historical well } \\
\text { production rate in the reservoir } \\
\text { Single completion: bottom-to-top }\end{array}$ \\
Completion type & $50-100$ bars, depending upon the \\
Minimum well bottom-hole pressure & segment performance \\
Maximum water cut & $95 \%$ \\
Minimum economic limit on oil rate & $1 \mathrm{~m}^{3} / \mathrm{day}$ \\
Maximum GOR constraint & $1500 \mathrm{~m}^{3} / \mathrm{m}^{3}$ \\
\hline
\end{tabular}

Table 5 Sensitivity parameters for horizontal well

\begin{tabular}{|c|c|c|c|c|}
\hline Rate $\left(\mathrm{m}^{3} /\right.$ day $)$ & 200 & 250 & 300 & \\
\hline $\begin{array}{l}\text { Offset (perforation bottom) } \\
\text { from WOC }(\mathrm{m})\end{array}$ & 5 & 10 & 15 & 20 \\
\hline Horizontal length (m) & 600 & 800 & 1000 & 1200 \\
\hline
\end{tabular}

Perforation top was assumed $2 \mathrm{~m}$ below GOC for all cases

completion to TD. Different packer length (Table 7) has been selected for simulation runs using ICD well completion.

\section{Equal length compartments with variable nozzle sizes- sensitivity on nozzle sizes}

Equally, spaced compartments with variable nozzle sizes designs are the preferred option if the reservoir is homogeneous with significant heel-to-toe pressure decline along the wellbore.

High-rate horizontal wells often suffer from the so-called heel-toe effect. This is caused by the frictional pressure gradient along the well, which means that the heel has a significantly lower pressure than the toe and so produces more fluid. This can lead to premature breakthrough of water or gas. A total of 35 cases have been examined for this case, details of all the cases are given in Table 8.

\section{Equal length compartments with variable nozzle sizes- uncertainty on nozzle sizes}

After determining most sensitive parameter from previous section, uncertainty analysis is carried out on variable A, B $\mathrm{E}$ and $\mathrm{F}$. Experimental design setup was done for the four variables using full factorial design which gives a total of 16 cases to be examined, additionally one central point has also been added to make the no. of simulation runs 17. Details of all the cases are given in Table 9.

\section{Results and discussion}

\section{Vertical well sensitivity results}

Results of sensitivity of vertical well are plotted in Fig. 6. It can be observed that cumulative production increases with increasing assigned rate from 50 to $150 \mathrm{~m}^{3} /$ day. Cumulative oil production increases with increase in offset from WOC. Incremental production is maximum by increasing the assigned rate from 50 to $100 \mathrm{~m}^{3} /$ day.

In bottom water reservoirs with active aquifer, proper planning and completion of the well(s) in vertical direction will require the consideration of fractional well penetration to achieve optimum critical oil production rate and breakthrough time (Okon et al. 2018).

Cumulative oil production increases with increase in offset from WOC and production rate. There are inverse relationships between water cut at end of prediction and cumulative oil produced, as well as between water cut at end of prediction and offset from WOC (Kumar et al. 2017a, b).

Controlling parameters for economical and optimal production rate from vertical well in a bottom water drive reservoir are optimum perforation interval and systematic approach (Gamal et al. 2016).

\section{Horizontal well sensitivity results}

Sensitivity results of horizontal well are plotted in Fig. 7. It can be observed that cumulative oil production increases by assigning higher withdrawal rates $\left(200,250,300 \mathrm{~m}^{3} /\right.$ day $)$. 
Table 6 List of cases for horizontal well

\begin{tabular}{|c|c|c|c|}
\hline S. no. & $\begin{array}{l}\text { Withdrawal rate } \\
\left(\mathrm{m}^{3} / \text { day }\right)\end{array}$ & $\begin{array}{l}\text { Offset from WOC } \\
(\mathrm{m})\end{array}$ & $\begin{array}{l}\text { Horizontal } \\
\text { length }(\mathrm{m})\end{array}$ \\
\hline 1 & 200 & 5 & 600 \\
\hline 2 & 200 & 5 & 800 \\
\hline 3 & 200 & 5 & 1000 \\
\hline 4 & 200 & 5 & 1200 \\
\hline 5 & 250 & 5 & 600 \\
\hline 6 & 250 & 5 & 800 \\
\hline 7 & 250 & 5 & 1000 \\
\hline 8 & 250 & 5 & 1200 \\
\hline 9 & 300 & 5 & 600 \\
\hline 10 & 300 & 5 & 800 \\
\hline 11 & 300 & 5 & 1000 \\
\hline 12 & 300 & 5 & 1200 \\
\hline 13 & 200 & 10 & 600 \\
\hline 14 & 200 & 10 & 800 \\
\hline 15 & 200 & 10 & 1000 \\
\hline 16 & 200 & 10 & 1200 \\
\hline 17 & 250 & 10 & 600 \\
\hline 18 & 250 & 10 & 800 \\
\hline 19 & 250 & 10 & 1000 \\
\hline 20 & 250 & 10 & 1200 \\
\hline 21 & 300 & 10 & 600 \\
\hline 22 & 300 & 10 & 800 \\
\hline 23 & 300 & 10 & 1000 \\
\hline 24 & 300 & 10 & 1200 \\
\hline 25 & 200 & 15 & 600 \\
\hline 26 & 200 & 15 & 800 \\
\hline 27 & 200 & 15 & 1000 \\
\hline 28 & 200 & 15 & 1200 \\
\hline 29 & 250 & 15 & 600 \\
\hline 30 & 250 & 15 & 800 \\
\hline 31 & 250 & 15 & 1000 \\
\hline 32 & 250 & 15 & 1200 \\
\hline 33 & 300 & 15 & 600 \\
\hline 34 & 300 & 15 & 800 \\
\hline 35 & 300 & 15 & 1000 \\
\hline 36 & 300 & 15 & 1200 \\
\hline 37 & 200 & 20 & 600 \\
\hline 38 & 200 & 20 & 800 \\
\hline 39 & 200 & 20 & 1000 \\
\hline 40 & 200 & 20 & 1200 \\
\hline 41 & 250 & 20 & 600 \\
\hline 42 & 250 & 20 & 800 \\
\hline 43 & 250 & 20 & 1000 \\
\hline 44 & 250 & 20 & 1200 \\
\hline 45 & 300 & 20 & 600 \\
\hline 46 & 300 & 20 & 800 \\
\hline 47 & 300 & 20 & 1000 \\
\hline 48 & 300 & 20 & 1200 \\
\hline
\end{tabular}

Table 7 Compartment length as an input to ICD cases

\begin{tabular}{l}
\hline Compartment length $(\mathrm{m})$ \\
\hline 100 \\
125 \\
150 \\
25 \\
50 \\
75 \\
\hline
\end{tabular}

For maximum recovery, horizontal well length should vary between 600 and $800 \mathrm{~m}$; additional increment in horizontal well length does not increase in oil production. Increasing horizontal well length from 600 to $1200 \mathrm{~m}$ does not increase the oil production cumulative linearly; maximum value is obtained for $800 \mathrm{~m}$ horizontal length in 36 cases out of 48 cases.

In bottom water reservoirs with active aquifer, placement of horizontal well should consider stand-off to drainage width as well as horizontal well length to drainage width to achieve optimum critical production rate and breakthrough time (Okan et al. 2018).

Offset from WOC, horizontal length, and withdrawal rate have an impact on cumulative oil production in case of horizontal well. Maximum impact on cumulative oil production is given by offset from WOC followed by withdrawal rate and last on horizontal well length (Kumar et al. 2017a, b).

\section{ICD sensitivity results}

\section{Sensitivity on compartment length}

To maximize cumulative oil production from ICD, it is pertinent to determine compartment length/number of nozzles and nozzle size in each ICD. Initially sensitivity on compartment length has been carried out and it is observed from Fig. 8 that, $150 \mathrm{~m}$ compartment length or seven nozzle ICD give maximum cumulative oil production.

\section{Sensitivity on nozzle sizes}

To determine nozzle size for each ICD for maximizing cumulative oil production, it is essential to determine which nozzle ICD is having maximum impact on recovery. A total of 39 cases have been run and results are plotted in form of a Tornado plot (Fig. 9) where variable which is most sensitive to recovery efficiency is on top and least sensitivity is on bottom. 
Table 8 Details of all the cases examined for variable nozzle sizes

\begin{tabular}{|c|c|c|c|c|c|c|c|c|}
\hline \multirow[t]{2}{*}{ Case } & \multicolumn{7}{|c|}{ Area of nozzle, $10^{-5} \mathrm{~m}^{2}$} & \multirow[t]{2}{*}{ \$RUN } \\
\hline & $\$ \mathrm{G}$ & $\$ F$ & $\$ E$ & $\$ D$ & $\$ \mathrm{C}$ & $\$ B$ & $\$ A$ & \\
\hline 2548_800_300_150_1 & 2.00 & 2.00 & 2.00 & 2.00 & 2.00 & 2.00 & 0.50 & 1 \\
\hline 2548_800_300_150_2 & 2.00 & 2.00 & 2.00 & 2.00 & 2.00 & 2.00 & 1.13 & 2 \\
\hline 2548_800_300_150_3 & 2.00 & 2.00 & 2.00 & 2.00 & 2.00 & 2.00 & 1.75 & 3 \\
\hline 2548_800_300_150_4 & 2.00 & 2.00 & 2.00 & 2.00 & 2.00 & 2.00 & 2.38 & 4 \\
\hline 2548_800_300_150_5 & 2.00 & 2.00 & 2.00 & 2.00 & 2.00 & 2.00 & 3.00 & 5 \\
\hline 2548_800_300_150_6 & 2.00 & 2.00 & 2.00 & 2.00 & 2.00 & 0.50 & 2.00 & 6 \\
\hline 2548_800_300_150_7 & 2.00 & 2.00 & 2.00 & 2.00 & 2.00 & 1.13 & 2.00 & 7 \\
\hline 2548_800_300_150_8 & 2.00 & 2.00 & 2.00 & 2.00 & 2.00 & 1.75 & 2.00 & 8 \\
\hline 2548_800_300_150_9 & 2.00 & 2.00 & 2.00 & 2.00 & 2.00 & 2.38 & 2.00 & 9 \\
\hline 2548_800_300_150_10 & 2.00 & 2.00 & 2.00 & 2.00 & 2.00 & 3.00 & 2.00 & 10 \\
\hline 2548_800_300_150_11 & 2.00 & 2.00 & 2.00 & 2.00 & 0.50 & 2.00 & 2.00 & 11 \\
\hline 2548_800_300_150_12 & 2.00 & 2.00 & 2.00 & 2.00 & 1.13 & 2.00 & 2.00 & 12 \\
\hline 2548_800_300_150_13 & 2.00 & 2.00 & 2.00 & 2.00 & 1.75 & 2.00 & 2.00 & 13 \\
\hline 2548_800_300_150_14 & 2.00 & 2.00 & 2.00 & 2.00 & 2.38 & 2.00 & 2.00 & 14 \\
\hline 2548_800_300_150_15 & 2.00 & 2.00 & 2.00 & 2.00 & 3.00 & 2.00 & 2.00 & 15 \\
\hline 2548_800_300_150_16 & 2.00 & 2.00 & 2.00 & 0.50 & 2.00 & 2.00 & 2.00 & 16 \\
\hline 2548_800_300_150_17 & 2.00 & 2.00 & 2.00 & 1.13 & 2.00 & 2.00 & 2.00 & 17 \\
\hline 2548_800_300_150_18 & 2.00 & 2.00 & 2.00 & 1.75 & 2.00 & 2.00 & 2.00 & 18 \\
\hline 2548_800_300_150_19 & 2.00 & 2.00 & 2.00 & 2.38 & 2.00 & 2.00 & 2.00 & 19 \\
\hline 2548_800_300_150_20 & 2.00 & 2.00 & 2.00 & 3.00 & 2.00 & 2.00 & 2.00 & 20 \\
\hline 2548_800_300_150_21 & 2.00 & 2.00 & 0.50 & 2.00 & 2.00 & 2.00 & 2.00 & 21 \\
\hline 2548_800_300_150_22 & 2.00 & 2.00 & 1.13 & 2.00 & 2.00 & 2.00 & 2.00 & 22 \\
\hline 2548_800_300_150_23 & 2.00 & 2.00 & 1.75 & 2.00 & 2.00 & 2.00 & 2.00 & 23 \\
\hline 2548_800_300_150_24 & 2.00 & 2.00 & 2.38 & 2.00 & 2.00 & 2.00 & 2.00 & 24 \\
\hline 2548_800_300_150_25 & 2.00 & 2.00 & 3.00 & 2.00 & 2.00 & 2.00 & 2.00 & 25 \\
\hline 2548_800_300_150_26 & 2.00 & 0.50 & 2.00 & 2.00 & 2.00 & 2.00 & 2.00 & 26 \\
\hline 2548_800_300_150_27 & 2.00 & 1.13 & 2.00 & 2.00 & 2.00 & 2.00 & 2.00 & 27 \\
\hline 2548_800_300_150_28 & 2.00 & 1.75 & 2.00 & 2.00 & 2.00 & 2.00 & 2.00 & 28 \\
\hline 2548_800_300_150_29 & 2.00 & 2.38 & 2.00 & 2.00 & 2.00 & 2.00 & 2.00 & 29 \\
\hline 2548_800_300_150_30 & 2.00 & 3.00 & 2.00 & 2.00 & 2.00 & 2.00 & 2.00 & 30 \\
\hline 2548_800_300_150_31 & 0.50 & 2.00 & 2.00 & 2.00 & 2.00 & 2.00 & 2.00 & 31 \\
\hline 2548_800_300_150_32 & 1.13 & 2.00 & 2.00 & 2.00 & 2.00 & 2.00 & 2.00 & 32 \\
\hline 2548_800_300_150_33 & 1.75 & 2.00 & 2.00 & 2.00 & 2.00 & 2.00 & 2.00 & 33 \\
\hline 2548_800_300_150_34 & 2.38 & 2.00 & 2.00 & 2.00 & 2.00 & 2.00 & 2.00 & 34 \\
\hline 2548_800_300_150_35 & 3.00 & 2.00 & 2.00 & 2.00 & 2.00 & 2.00 & 2.00 & 35 \\
\hline
\end{tabular}

A, B, C, D and E are nozzle sizes for ICD at compartment length of $150 \mathrm{~m}$ 
Table 9 List of uncertain variables for cases examined

\begin{tabular}{llllll} 
Case & \multicolumn{3}{l}{ Nozzle cross-sectional area, } & \multirow{2}{*}{ \$LOOP } \\
\cline { 2 - 5 } & \multicolumn{1}{l}{$10^{-5} \mathrm{~m}^{2}$} & & \\
\cline { 2 - 5 } & \$F & \$E & \$B & \$A & \\
\hline 2548_800_300_150_36 & 1.750 & 1.750 & 1.750 & 1.750 & 1 \\
2548_800_300_150_37 & 0.500 & 0.500 & 0.500 & 0.500 & 2 \\
2548_800_300_150_38 & 0.500 & 0.500 & 0.500 & 3.000 & 3 \\
2548_800_300_150_39 & 0.500 & 0.500 & 3.000 & 0.500 & 4 \\
2548_800_300_150_40 & 0.500 & 0.500 & 3.000 & 3.000 & 5 \\
2548_800_300_150_41 & 0.500 & 3.000 & 0.500 & 0.500 & 6 \\
2548_800_300_150_42 & 0.500 & 3.000 & 0.500 & 3.000 & 7 \\
2548_800_300_150_43 & 0.500 & 3.000 & 3.000 & 0.500 & 8 \\
2548_800_300_150_44 & 0.500 & 3.000 & 3.000 & 3.000 & 9 \\
2548_800_300_150_45 & 3.000 & 0.500 & 0.500 & 0.500 & 10 \\
2548_800_300_150_46 & 3.000 & 0.500 & 0.500 & 3.000 & 11 \\
2548_800_300_150_47 & 3.000 & 0.500 & 3.000 & 0.500 & 12 \\
2548_800_300_150_48 & 3.000 & 0.500 & 3.000 & 3.000 & 13 \\
2548_800_300_150_49 & 3.000 & 3.000 & 0.500 & 0.500 & 14 \\
2548_800_300_150_50 & 3.000 & 3.000 & 0.500 & 3.000 & 15 \\
2548_800_300_150_51 & 3.000 & 3.000 & 3.000 & 0.500 & 16 \\
2548_800_300_150_52 & 3.000 & 3.000 & 3.000 & 3.000 & 17 \\
\hline
\end{tabular}

Valve size for remaining ICD is $5 \mathrm{e}-6 \mathrm{~m}^{2}$

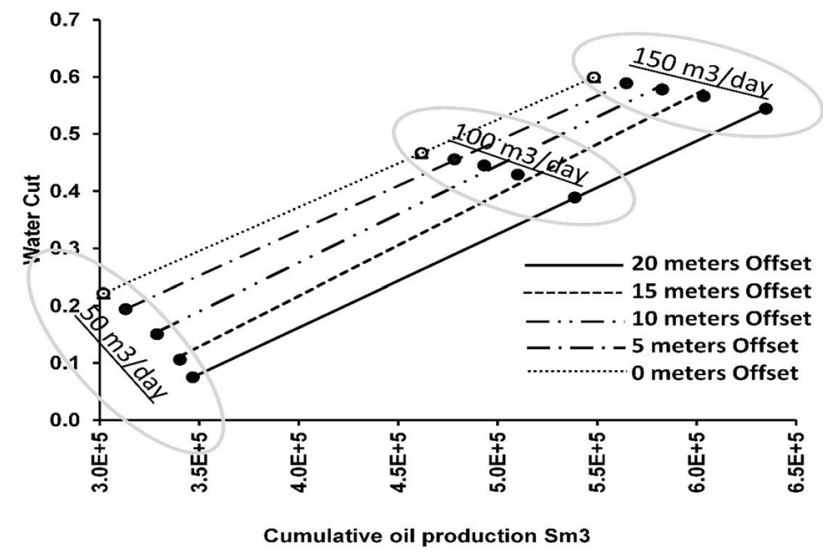

Fig. 6 Sensitivity results of vertical well
Equal length compartments with variable nozzle sizesuncertainty on nozzle sizes

Nozzles B, F, E and A have maximum impact on recovery and hence a detailed uncertainty analysis has been run. A comparison of oil production cumulative is done in Fig. 10 for all the cases examined. Figure 11 compares the production profile of minimum (2548_800_300_150_50) and maximum recovery (2548_800_300_150_39) efficiency.

The number of ICDs, the number of nozzles in each ICD, and the size of nozzles are optimized to maximize the oil production for different reservoir condition. This optimal design, which consisted of five compartments in the horizontal section with 14 ICD joints, proved to be more effective in delaying water breakthrough and increasing recovery (Maalouf et al. 2017).

\section{Economics and recovery factor}

Economics and recovery efficiency for various cases has been compared in form of a table which is presented in Table 10. Table 11 lists all the assumptions in working out the economics.

\section{Conclusions}

Withdrawal rate and offset from WOC have an effect on oil production for vertical well. From sensitivity study on offset and withdrawal rate, it was observed that offset has more impact on cumulative oil production than withdrawal rate. Highest recovery of $0.63 \mathrm{MMm}^{3}$ cumulative oil is obtained using offset of $20 \mathrm{~m}$ and initial withdrawal rate of $150 \mathrm{~m}^{3} /$ day.

Horizontal well length, offset from WOC and withdrawal rate have an effect on oil production for horizontal well. Highest impact on oil production is given by offset from WOC; second big effect is given by withdrawal rate and 


\section{Cumulative LquidVs pressure drop}

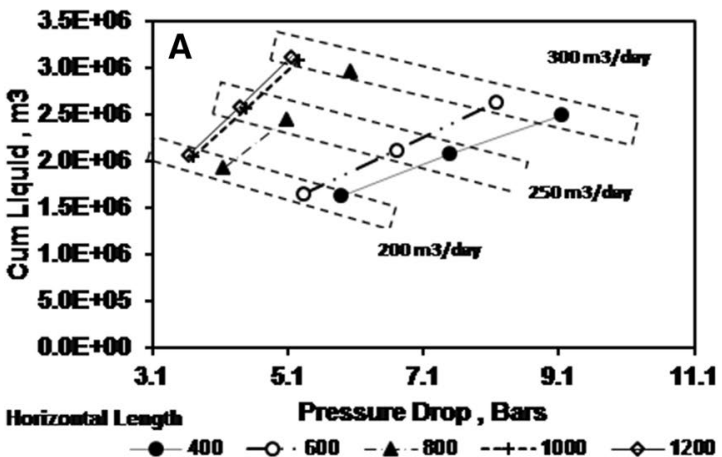

Cumulative oiv Vs horizontallength

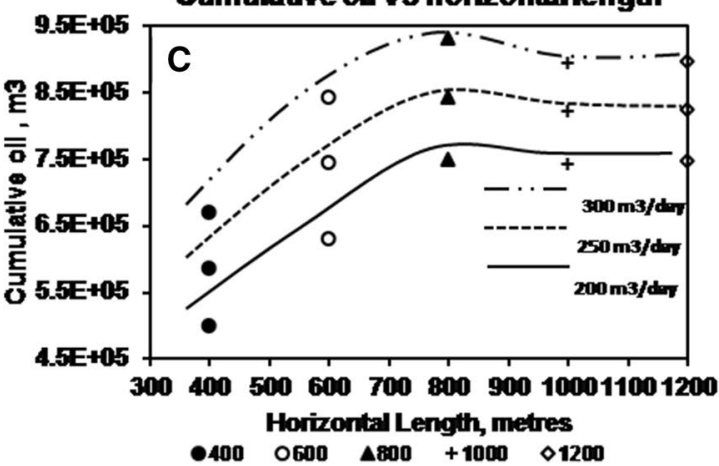

Fig. 7 Sensitivity results of horizontal well

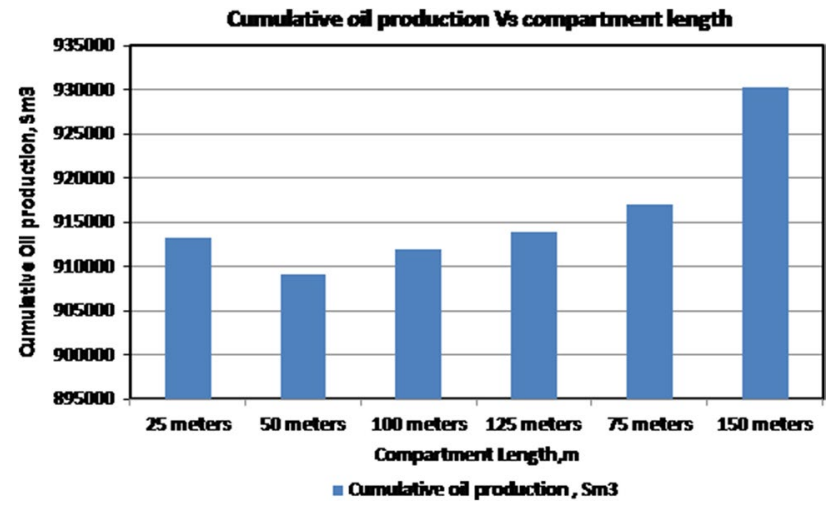

Fig. 8 Sensitivity results of compartment length
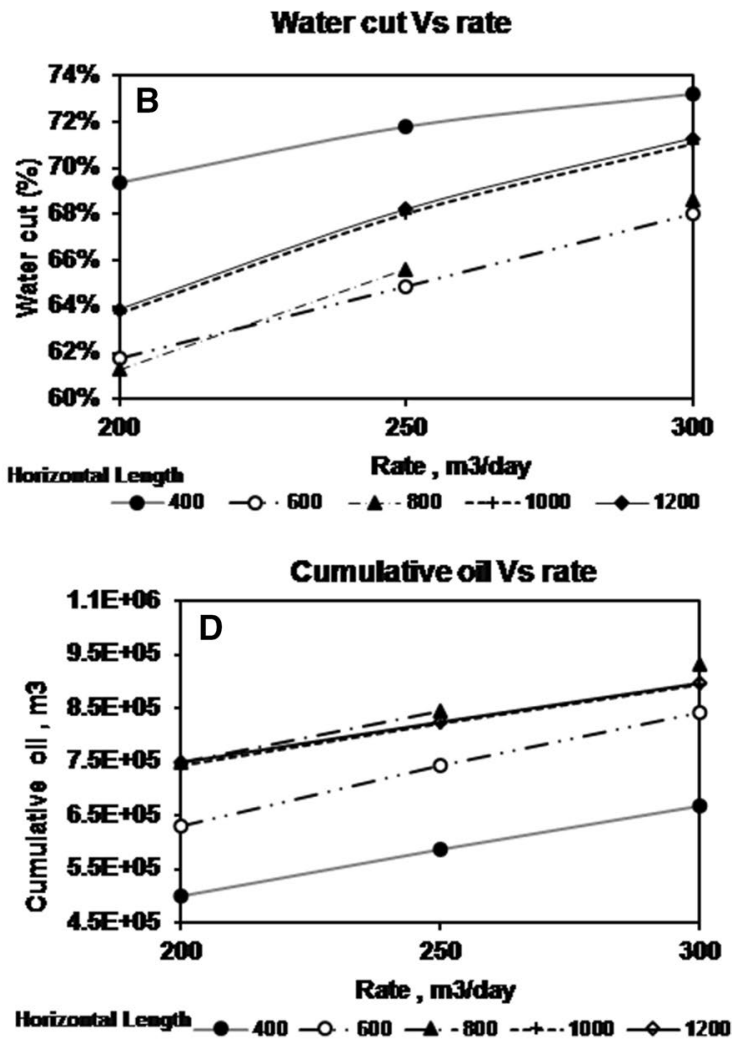

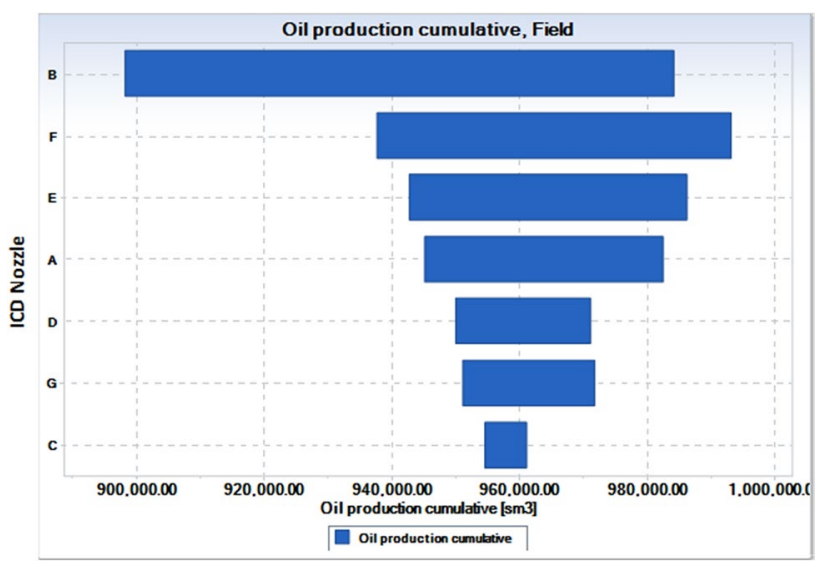

Fig. 9 Tornado plot 


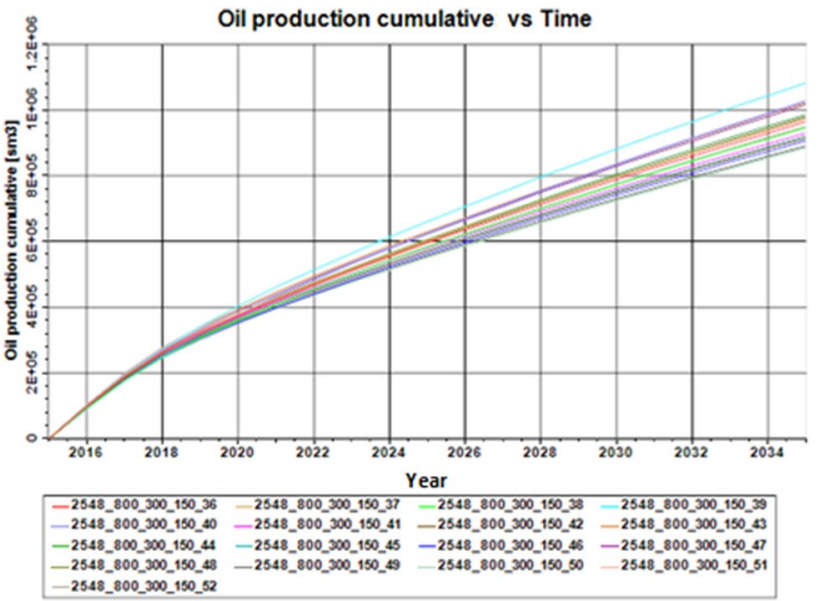

Fig. 10 Comparison of oil production cumulative for different nozzle sizes finally horizontal well length effects oil production. Highest recovery of $0.95 \mathrm{MMm}^{3}$ cumulative oil is obtained using optimal horizontal well length varying between 600 and $800 \mathrm{~m}$ offset of $20 \mathrm{~m}$ and initial withdrawal rate of $300 \mathrm{~m}^{3} /$ day. Above results when compared with producing well number 49 , cumulative oil production of $0.152 \mathrm{MMm}^{3}$ is achieved during the entire production history with offset of $10 \mathrm{~m}$, horizontal well length of $400 \mathrm{~m}$ and initial withdrawal rate at $200 \mathrm{~m}^{3} /$ day.

Compartment length and nozzle size have an effect on oil production for smart horizontal well (ICD). Maximum effect on oil production is given by nozzle size in each ICD followed by compartment length. Seven ICDs and compartment length of $150 \mathrm{~m}$ with variable nozzle sizes give maximum recovery with cumulative oil production of $1.08 \mathrm{MMm}^{3}$.
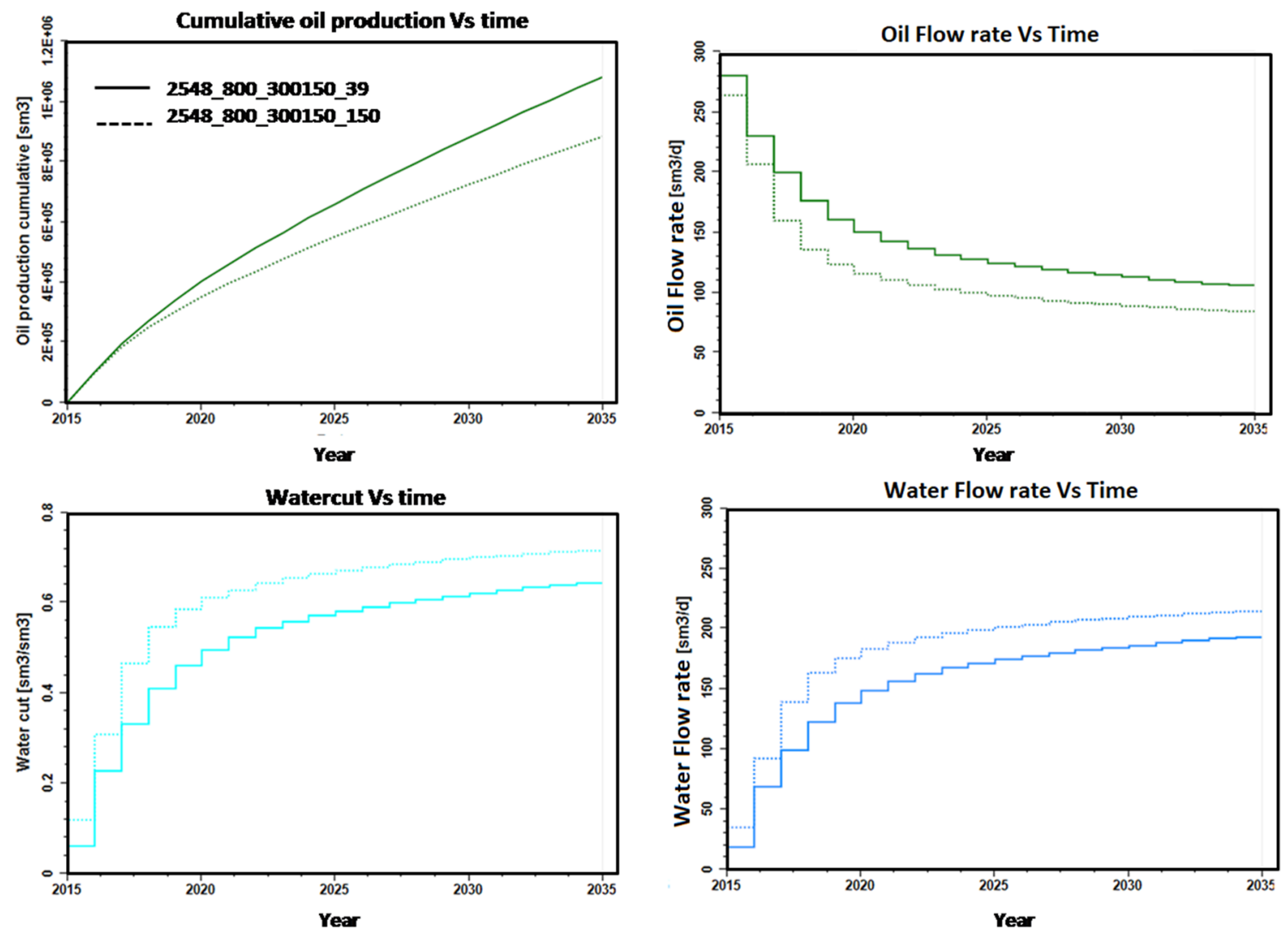

Fig. 11 Production profile comparison of minimum and maximum recovery 
Table 10 Results for various sensitivity cases

\begin{tabular}{llllll}
\hline Cases & No. of wells & Cum oil $\left(\mathrm{MMm}^{3}\right)$ & NPV (crores) & $\begin{array}{l}\text { Oil in place } \\
\left(\mathrm{MMm}^{3}\right)\end{array}$ & $\begin{array}{l}\text { Recovery } \\
\text { factor } \\
(\%)\end{array}$ \\
\hline Vertical well & 1 & 0.6348 & 323 & 1.56 & 40 \\
Horizontal well & 1 & 0.9316 & 495 & 2.17 & 43 \\
Horizontal well + ICD & 1 & 1.086 & 589 & 2.17 & 50 \\
\hline
\end{tabular}

Table 11 Economic assumptions

\begin{tabular}{ll}
\hline Drilling cost-vertical well & Rs. $60,000 / \mathrm{m}$ \\
Drilling cost-horizontal well & Rs. $1,20,000 / \mathrm{m}$ \\
Sales price oil & $\$ 50 / \mathrm{bbl}$ \\
Sale price gas & $\$ 3 / \mathrm{MMBTU}$ \\
Operating costs for crude oil is Rs. $2275 / \mathrm{m}^{3}$ & \\
Operating costs for gas is Rs. 2025/1000 scum & \\
Tax calculated is $33.20 \%$ of [revenue-(drilling expenditure + wo \\
$\quad$ expenditure + operating expenditure)]
\end{tabular}

Open Access This article is distributed under the terms of the Creative Commons Attribution 4.0 International License (http://creativeco mmons.org/licenses/by/4.0/), which permits unrestricted use, distribution, and reproduction in any medium, provided you give appropriate credit to the original author(s) and the source, provide a link to the Creative Commons license, and indicate if changes were made.

\section{References}

Al Hasani MA, Al Khayari SR, Al Maamari R, Al-Wadhahi MA (2008) Diagnosis of excessive water production in horizontal wells using WOR plots. Int Pet Technol Conf. https://doi.org/10.2523/IPTC11958-MS

Al Qahtani A, Al Hashim H, Al Yousef H (2015) A new approach for optimization of long horizontal wells' performances. Int Pet Technol Conf. https://doi.org/10.2523/IPTC-18372-MS

Dosunmu I, Osisanya S (2015) An economic approach to horizontal well length optimization. Soc Pet Eng. https://doi. org/10.2118/177866-MS

Ellis T, Erkal A, Jokela T, Kvernstuen S, Leung E, Moen T, Porturas F, Skillingstad T, Vorkinn PB, Raffn AG, Gordon G (2009) Inflow control devices-raising profile. Oilfield Rev Winter 21:30-37

Forouzanfar F, Reynolds AC (2013) Well-placement optimization using a derivative-free method. J Pet Sci Eng 109:96-116
Gamal M, Khairy M, El-Banbi AH, Saad SM (2016) An approach for determination of the economically optimal production controlling parameters from water drive oil reservoirs. Soc Pet Eng. https:// doi.org/10.2118/182842-MS

Kumar M, Sharma P, Gupta DK (2017a) Optimization of vertical well completion in a saturated reservoir with bottom water drive for maximizing recovery. Biofuels. https://doi.org/10.1080/17597 269.2017.1284472

Kumar M, Sharma P, Gupta DK (2017b) Sensitivity study of horizontal length, offset from water oil contact and withdrawal rate of horizontal well in bottom water drive reservoir. J Pet Explor Prod Technol 8(2):577-588. https://doi.org/10.1007/s1320 2-017-0348-9

Maalouf CB, Zidan M, Uijttenhout M, Hernandez EJ, Al-Jaberi S, Saeed Y, Graham RA (2017) Responsive design of inflow control devices completions for horizontal wells. Soc Pet Eng. https://doi. org/10.2118/188794-MS

Mojaddam Zadeh A, Slotte PA, Gyllensten AJ, Aasheim R, Årland K (2012) Optimal inflow control devices configurations for oil rim reservoirs. Offshore Technol Conf. https://doi.org/10.4043/22963 -MS

Okon AN, Appah D (2018) Water coning prediction: an evaluation of horizontal well correlations. Eng Appl Sci 3(1):21-28. https://doi. org/10.11648/j.eas.20180301.14

Okon AN, Appah D, Akpabio JU (2018) A critical evaluation of water coning correlations in vertical wells. Am J Sci Eng Technol 3(1):1-9. https://doi.org/10.11648/j.ajset.20180301.11

Schlumberger (2015) ECLIPSE simulation manuals, eclipse technical description

Schlumberger PETREL* (2015) E\&P Software Platform, user manual, version 2015.1

Wagenhofer T, Hatzignatiou DG (1996) Optimization of horizontal well placement. Paper presented at Society of Petroleum Engineers Western Regional meeting held in Anchorage, Alaska, 22-24 May

Publisher's Note Springer Nature remains neutral with regard to jurisdictional claims in published maps and institutional affiliations. 